\title{
Pyrrolic Nitrogen-containing Hierarchical Porous Biocarbon for Enhanced Sodium-ion Energy Storage
}

Elayaperumal Sujithkrishnan ${ }^{1}$, Arul Prasath ${ }^{1}$, Mani Govindasamy ${ }^{2}$, Razan Abdullah Alshgari ${ }^{2}$ and Perumal Elumalai $1, *$

${ }^{1}$ Electrochemical Energy and Sensors Lab, Department of Green Energy Technology,

Madanjeet School of Green Energy Technologies, Pondicherry University,

Puducherry-605014, India

${ }^{2}$ Chemistry Department, Collage of Science, King Saud University, Riyadh 11541, Saudi Arabia

*Corresponding Author.

E-mail: elumalai.get@pondiuni.edu.in; drperumalelumalai@gmail.com (P. Elumalai)

Tel.: +91-413-2654867 

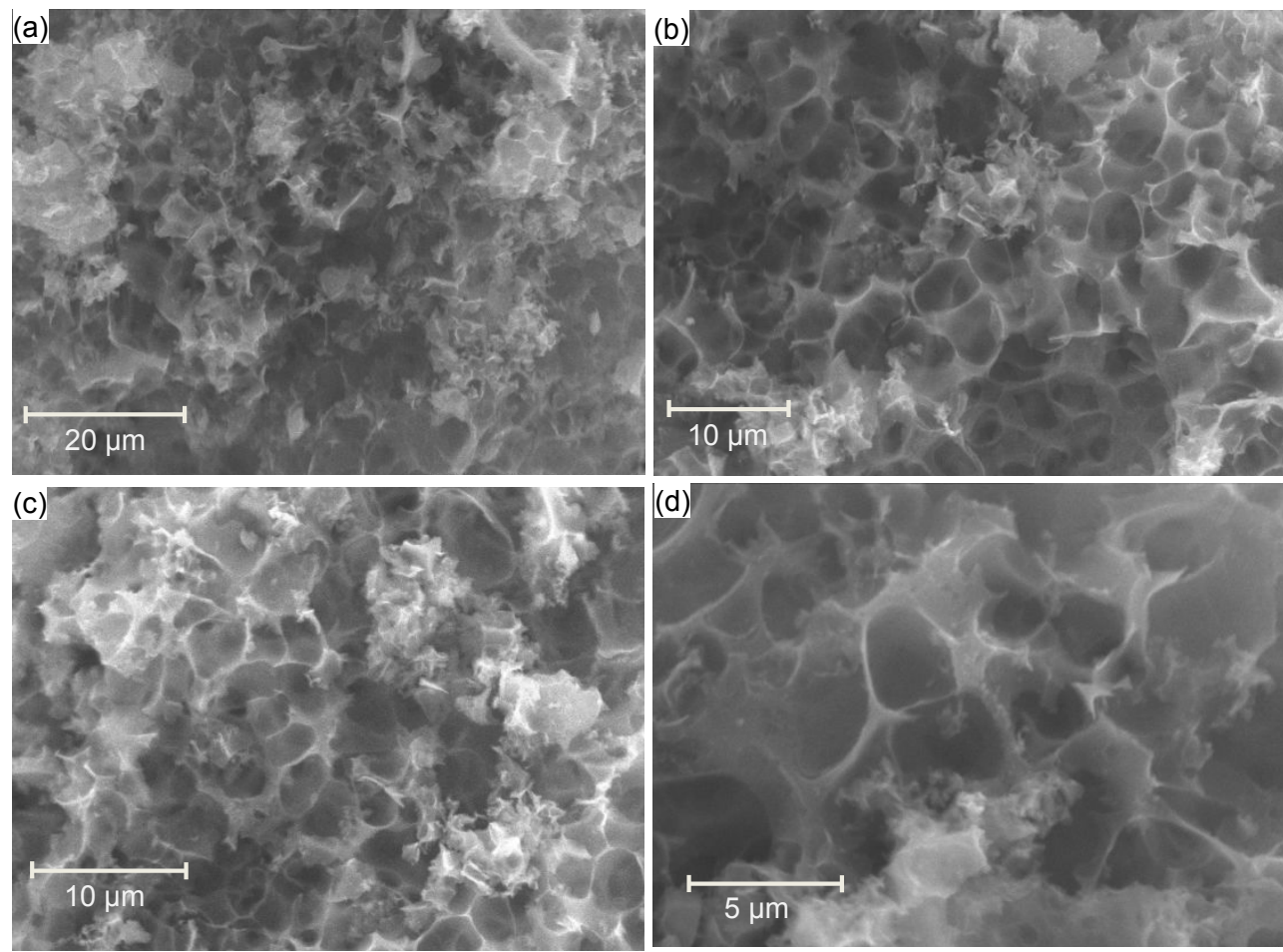

Figure S1. SEM images at different magnifications recorded for the AAC sample. 

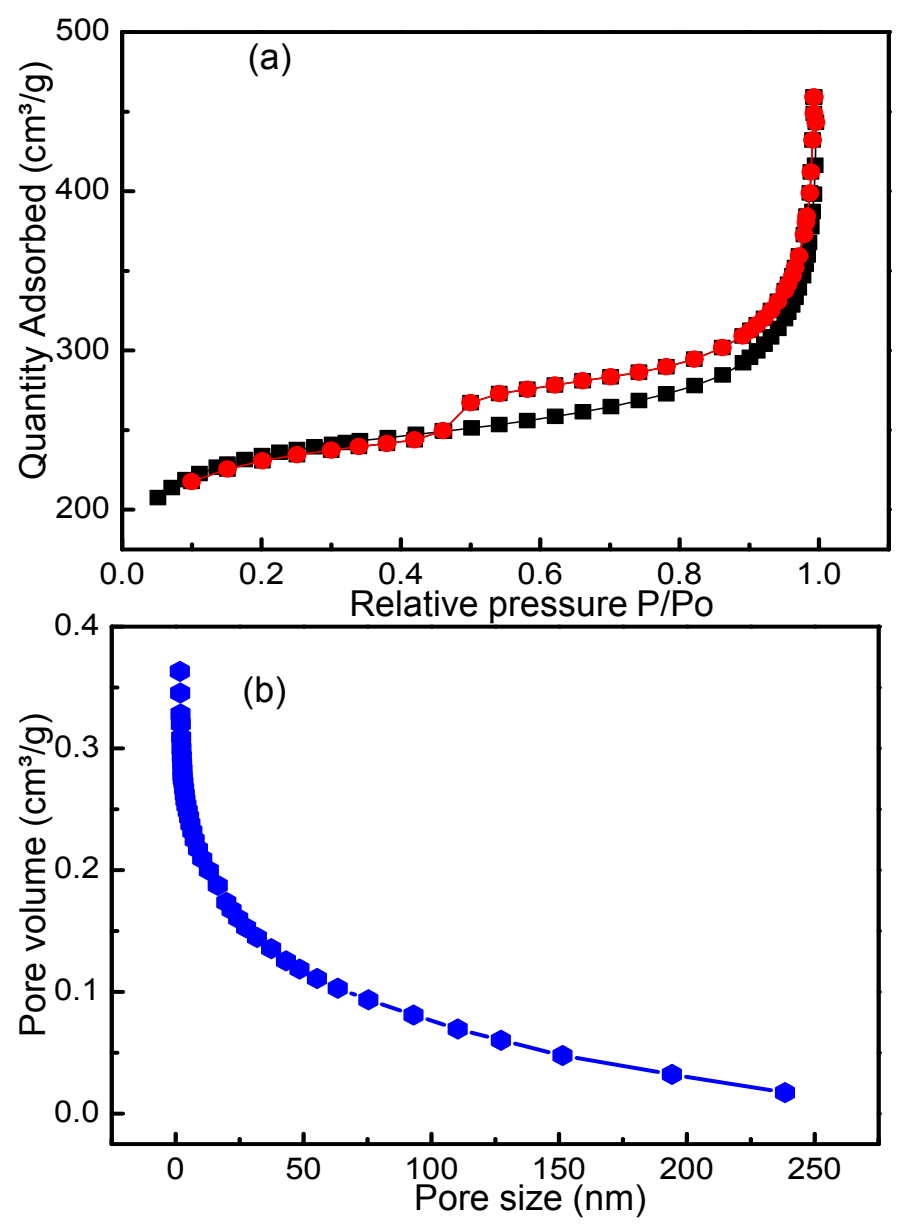

Figure S2. (a) $\mathrm{N}_{2}$ adsorption-desorption isotherm curve and (b) $\mathrm{BJH}$ pore size distribution recorded for the AAC sample. 


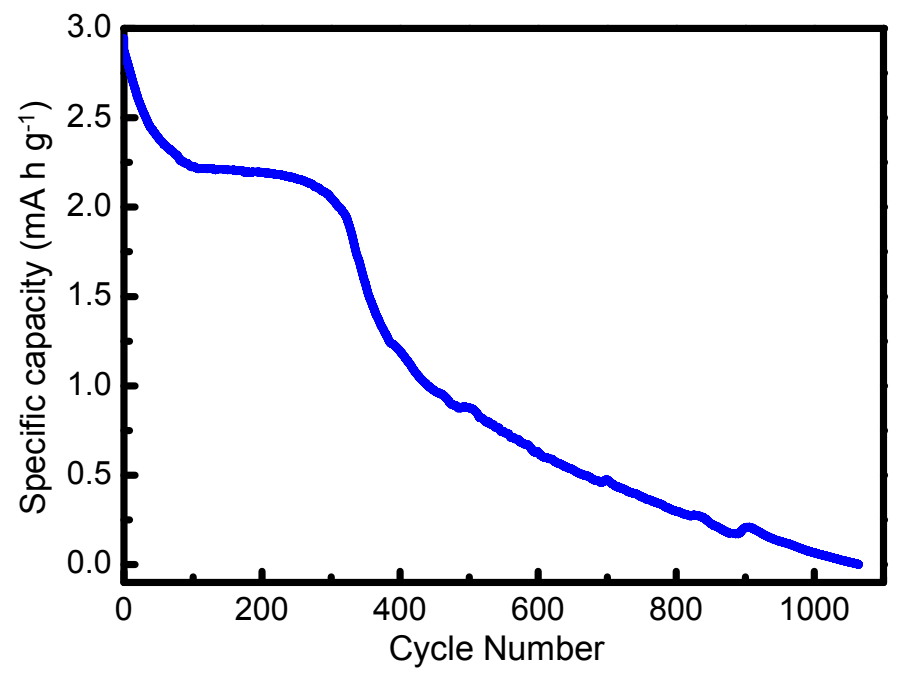

Figure S3. Initial discharge curve recorded for the CR-2032 coin cell consisting of the activated biocarbon as anode and sodium metal as counter electrode at $0.1 \mathrm{C}$-rate. 


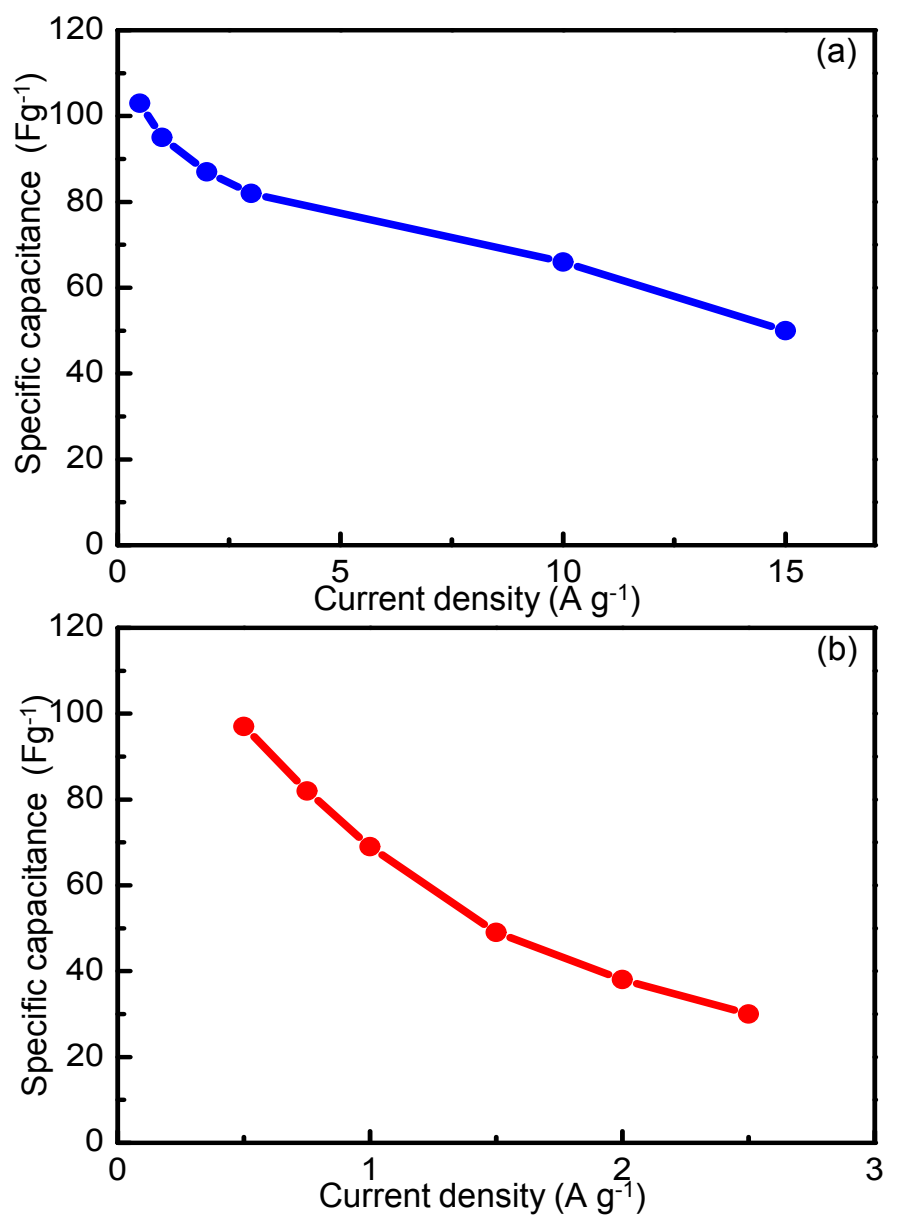

Figure S4. Dependence of device capacitance on current density for (a) aqueous and (b) nonaqueous ultracapacitor devices. 